\title{
LiTiMg ferrite substrate for circular array of circular patches under external magnetic field
}

\author{
Naveen Kumar Saxena ${ }^{1}$, Moh. Ayub Khan ${ }^{2}$, Nitendar Kumar ${ }^{3}$ and P.K.S. Pourush ${ }^{1}$ \\ ${ }^{1}$ Microwave Lab, Dept. of Physics, Agra College, Agra- 282002 (U.P), India. \\ ${ }^{2}$ Dept. of Electronics \& Communication, Anand Engineering College, Agra, India. \\ ${ }^{3}$ Solid State Physics Laboratory, Timarpur, Delhi- 110007 , India. \\ nav3091@rediffmail.com; ayubkhan48@rediffmail.com; nitendar@rediffmail.com; ppourush@yahoo.co.in
}

\begin{abstract}
A circular array of eight microstrip circular patches modeled on synthesized LiTiMg ferrite substrate has been investigated under the externally applied perpendicular DC magnetic field. LiTiMg ferrite substrate has been synthesized by the Solid State Reaction Technique (SSRT). Here, we also presented a comparison of radiation pattern and some other parameters, when the antenna array is biased and unbiased. Having LiTiMg substrate with perpendicular magnetic field, we reported a reduction of side-lobes, increased directivity and better radiation power response of array.
\end{abstract}

Keywords: Substituted Li ferrite; microstrip array antenna; X-band frequency range.

\section{List of symbols}

$\mathrm{F}_{\mathrm{R}}=$ resonant frequency; $\mathrm{h}=$ height of substrate; $\mathrm{a}=$ radius of patch; $\mathrm{a}_{\text {eff }}=$ effective radius of patch; $\varepsilon_{\mathrm{r}}=$ dielectric constant; $\varepsilon_{\text {eff }}=$ effective dielectric constant; $\mu_{\mathrm{r}}=$ initial permeability; $\mu_{\mathrm{eff}}=$ effective permeability; $\mathrm{K}_{\mathrm{d}}=$ ordinary propagation constant; $\mathrm{K}_{\mathrm{e}, \pm}=$ extraordinary propagation constant; $\mathrm{w}=$ angular frequency; $\mathrm{J}_{\mathrm{n}+1}=(\mathrm{n}+1)^{\text {th }}$ order Bessel's function of first kind; $J_{n-1}=(n-1)^{\text {th }}$ order Bessel's function of first kind; $H=$ bias field; $\lambda=$ wavelength; $4 \Pi M_{s}=$ saturation magnetization; $Y=$ gyromagnetic ratio (2.8 $\mathrm{MHz} /$ Oe.).

\section{Introduction}

Some extra ordinary characteristics of polycrystalline ferrite over normal dielectric material make it very useful in microwave antenna applications. Different types of polycrystalline ferrites have their specific advantages as Li substituted ferrites has high dielectric constant, low sintering temperature etc. than other substituted ferrites. The reason for using ferrite materials in microstrip structures is that the applied magnetic field changes the permeability and thus the electrical properties of material, which in turn changes the antenna properties. The significance of this is that it is possible to change the antenna characteristics through the DC magnetic field applied externally.

The integration of ferrite technology into microstrip printed circuit antenna has numerous advantages and potential applications. Beam steering, gain and bandwidth enhancement, RCS control, surface wave reduction, switchable and electronic tunability are some of the unique and inherent features of ferrite based microstrip antennas and arrays, which have been discussed by numbers of investigators in recent years (Pozar, 1992; Batchelor et al., 1997, Pourush \& Dixit, 1998; Bharadwaj et al., 2001). In the present paper, the concept of tunable antenna has been developed by taking a eight elements circular array of circular patches printed on LiTiMg ferrite substrate in an $\mathrm{X}$ band of microwave frequency range.

Theory

The circular array geometry is shown in Fig. 1. It consists of 8 identical elements of radius 'a' printed on LiTiMg ferrite substrate of thickness ' $h$ '. The dielectric constant and saturation magnetization $\left(4 \sqcap M_{s}\right)$ of substrate is 15 and 2200 Gauss respectively.

For a biased ferrite substrate, a normal incident plane wave may excite two types of waves (ordinary and extraordinary wave). In the case of normal incident magnetic field biasing ordinary wave is same as the plane wave in the dielectric slab. On the other hand, the extraordinary wave is a TE mode polarized parallel to the biasing direction with its phase propagation constant Ke (Pozar, 1992; Pourush \& Dixit, 1998).

$$
\begin{aligned}
& K_{\epsilon}=\frac{W}{G} \sqrt{e_{6 f f} \times H_{6 f f}} \\
& R_{\mathrm{L}}=\frac{W}{G} \sqrt{e_{\Im f f}} \\
& \mu_{G f f}=\frac{\mu^{2}-k^{2}}{\mu i} \\
& k=1+\frac{W_{o} W_{m}}{w_{a}^{2}-w^{2}} \\
& i=\frac{w w_{m}}{w_{a}^{2}-w F^{2}}
\end{aligned}
$$

Where,

$$
w_{o}=\gamma H_{\sigma} \text { and } w_{m}=\gamma 4 \pi M_{s}
$$

"LiTiMg ferrite substrate" http://www.indjst.org
Naveen et al. Indian J.Sci.Technol. 
where $H_{\circ}$ is the bias field, $\left(4 \sqcap M_{s}\right)$ is the saturation magnetization, $\mathrm{Y}$ is the gyromagnetic ratio as $\mathrm{Y}=2.8$ $\mathrm{MHz} / \mathrm{Oe}$. The frequency range of negative $\mu_{\text {off }}$ is:

$$
\left[w_{Q}\left(w_{Q}+w_{m}\right)\right]^{1 / 2} \kappa_{m} w \alpha_{m}\left(w_{Q}+w_{m}\right)
$$

The frequency limits define the approximate range within and around which the ferrite exhibit interesting microwave characteristics. The use of the biased field is to control the properties of the extraordinary wave which results a polarized switchable antenna. The antenna is off when extraordinary waves propagate with negative $k_{e f f}$. The dispersion curve for this array geometry for four values of biasing is given in Fig. 2 .

It is evident from the dispersion effect on ferrite material that there should be a propagating and nonpropagating region for an antenna. There is a frequency range bounded by limits, namely cutoff limit or resonance limit. In this where $\mu_{\text {off }}$ is negative, the extraordinary wave is highly attenuating and therefore the antenna is effectively off as radiator.

\section{Synthesis of substrate}

LiTiMg ferrite has been synthesized using solid state reaction technique (SSRT). The ingredients required for the preparation of these ferrites were calculated on the basis of chemical formula. A small amount of $\mathrm{Mn}^{3+}$ ion was also incorporated in the basic composition in order to suppress the formation of $\mathrm{Fe}^{2+}$ ions in the ferrites and to influence megnetostriction being a John Teller ion (Van, 1956). In order to avoid Lithia at high temperatures of sintering, $\mathrm{Bi}_{2} \mathrm{O}_{3}(0.25$ wt \%) was added as sintering aid (Pran Kishan et al., 1985). Analytical grade chemicals were used for the preparation of the material. The stoichiometric ratio of the chemicals was thoroughly mixed in a polypropylene jar containing the zirconium balls \& distilled water was used as a mixing agent. The presintering of the mixed powder has been carried out at $\sim 750^{\circ} \mathrm{C}$ in a box furnace and soaking time was kept 4 hours. The sieved material was pressed in disk (antenna substrate) and toroidal shapes with the help of suitable dies and using hydraulic pressing technique at pressure of $10 \mathrm{ton} / \mathrm{cm}^{2}$. The substrates and toroidals were finally sintered at $1050^{\circ} \mathrm{C}$ for four hours. The heating and cooling cycle of the samples was carried out in the air atmosphere of furnace. The sintered sample so obtained was subjected to cutting, grinding, polishing etc. in order to get specific size and shape. The important material properties such as magnetic and electrical properties were studied (Randhawa et al., 2007). The electrical and magnetic properties of LiTiMg ferrite substrate have been experimentally calculated and are presented in Table 1.

Research article

CIndian Society for Education and Environment (iSee)
Table 1. The electrical \& magnetic properties of LiTiMg ferrite substrate

\begin{tabular}{|c|c|}
\hline $\begin{array}{c}\text { LiTiMg Ferrite } \\
\text { Characteristics }\end{array}$ & Values \\
\hline $\begin{array}{c}\text { Magnetic } \\
\text { Saturation }\left(A m M_{S}\right)\end{array}$ & $\begin{array}{c}2200 \\
\text { Gauss }\end{array}$ \\
\hline Curie Temp. $\left(\mathrm{T}_{\mathrm{c}}\right)$ & $325 \mathrm{~K}$ \\
\hline Density $(\rho)$ & $\begin{array}{c}4.21 \\
\text { grams } / \mathrm{cm}^{3}\end{array}$ \\
\hline Remanence & 0.90 \\
\hline Coercivity & 2.54 \\
\hline Dielectric & 15 \\
\hline Constant $(\varepsilon)$ & 290 \\
\hline $\begin{array}{c}\text { Resonance } \\
\text { Line Width }(\Delta \mathrm{H})\end{array}$ & Oersteds \\
\hline Loss Tangent $(\tan \delta)$ & $<0.0009$ \\
\hline
\end{tabular}

"LiTiMg ferrite substrate" http://www.indjst.org
Vol. 3 No. 3 (Mar 2010)

ISSN: 0974- 6846

\section{Simulation and characterization}

The dimensions of each element are calculated by following equations:

$$
f_{r}=\frac{K_{m m} \in}{2 \pi \alpha_{\text {fff }} \sqrt{e_{r} k_{r}}}
$$

The above equation is based on the Cavity model. Using the pattern multiplication approach and neglecting mutual coupling between the elements, the normalized form of the array factor for the present geometry is obtained and given below (Balh et al., 1980; Balanis, 1997).

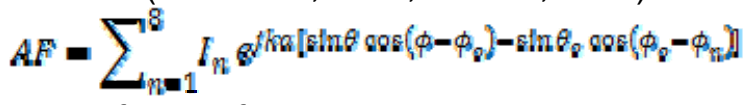

The total fields of the present array geometry can be expressed by the field of single element multiplied by array factor. Thus the far zone expressions for circular patch microstrip antenna are obtained as follow:

$$
\begin{aligned}
& E_{\theta t}=f^{n} \frac{k a V \theta-j k r}{2 r} \operatorname{cosn} \varphi \frac{\sin (k h \cos \theta)}{k h \cos \theta} \\
& \times U_{n+1}(k a \sin \theta)-I_{n-1}(k a s \ln \theta) \\
& E_{\varphi t}=f^{n} \frac{k \alpha V \theta-j k r}{2 r} \operatorname{cosn} \varphi \frac{\operatorname{sh}(k h \cos \theta)}{k h \cos \theta} \\
& \left.\times U_{n+1}(k \kappa \operatorname{sh} \theta)+I_{n-1}(k \kappa s h \theta)\right]
\end{aligned}
$$

Where,

$$
k=K_{ \pm}=K_{d}\left(\frac{w_{q}+w_{m} \mp w}{w_{q} \mp w_{m}}\right)^{1 / 2}
$$

The parameters related to patch characterization are calculated for biased and unbiased ferrite substrate, listed in Table 2. By the help of these parameters and mathematical software (Mathworks MatLab 7.1), the comparison of radiation patterns are plotted in fig. 3-8 for E-plane, H-plane and array for this geometry. These curves show a comparison between unbiased and biased substituted polycrystalline ferrite substrate array antenna. The total field pattern $R(\theta, \varphi)$ is generally obtained from the relation:

$R(\theta, \varphi)=\left|E_{\theta t}\right|^{2}+\left|E_{\varphi t}\right|^{2}$ The value of $R(\theta, \varphi)$ are computed for a case taking source frequency $f=10 \mathrm{GHz}, k=K_{n}, \epsilon_{\mathrm{q}}=15, h=0.165 \mathrm{~cm}$, $a_{\text {eff }}=0.2104 \mathrm{~cm}$ and loss tangent $=$ 0.0005 (Sodha \& Srivastav, 1981; Jain, 1993).

\section{Conclusions}

The radiation patterns and antenna's characteristics are calculated and reported in Fig. 3-5 and 
Fig. 1. Geometry of eight elements circular array microstrip circular patch antenna

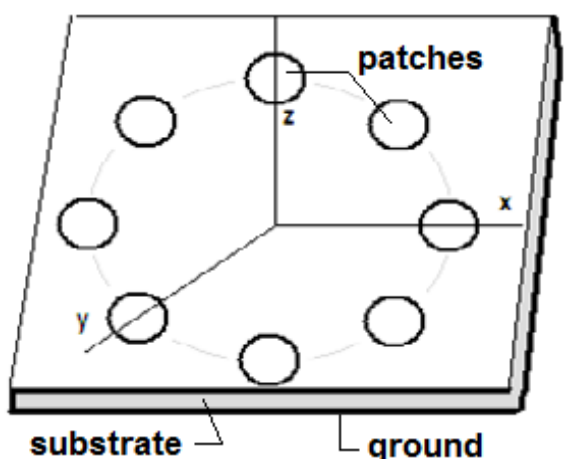

Fig. 2. Dispersion curve ( $f$ Vs. K) for plane wave

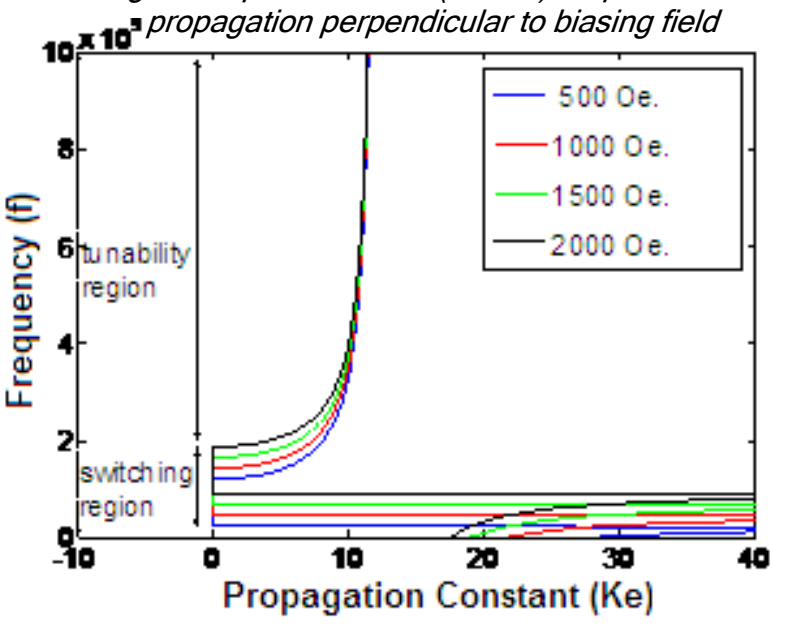

Fig. 4. Comparison of H-plane pattern of circular patch microstrip antenna with RHCP for biased case \& unbiased case

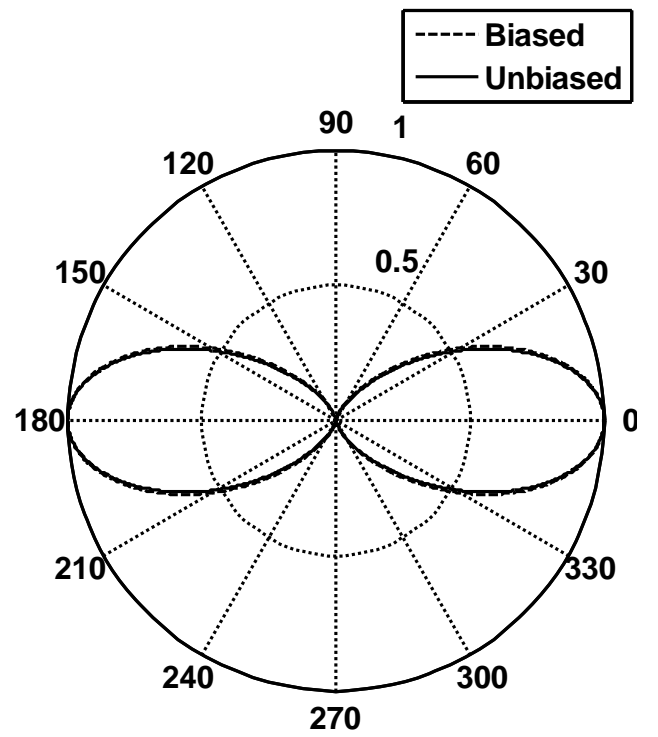

Table 2. Comparison of antenna 's parameters for unbiased and biased case

\begin{tabular}{|c|c|c|}
\hline Parameters & Unbiased & Biased \\
\hline Total Impedance $\left(\mathrm{Z}_{\text {in }}\right)$ & $936.21 \mathrm{ohms}$ & $110.83 \mathrm{ohms}$ \\
\hline Admittance $(\mathrm{Y})$ & $0.0005 \mathrm{mhos}$ & $0.0045 \mathrm{mhos}$ \\
\hline Quality Factor $(\mathrm{Q})$ & $\sim 30 \%$ & $\sim 30 \%$ \\
\hline Bandwidth $(\mathrm{BW})$ & $\sim 34 \mathrm{~dB}$ & $\sim 34 \mathrm{~dB}$ \\
\hline Directivity Gain $(\mathrm{D})$ & 3.53 & 10.51 \\
\hline Radiation Power $\left(\mathrm{P}_{\mathrm{r}}\right)$ & $0.267 \mathrm{~mW}$ & $2.3 \mathrm{~mW}$ \\
\hline
\end{tabular}

Fig. 3. Comparison of E-plane pattern of circular patch microstrip antenna with RHCP for biased case and unbiased case

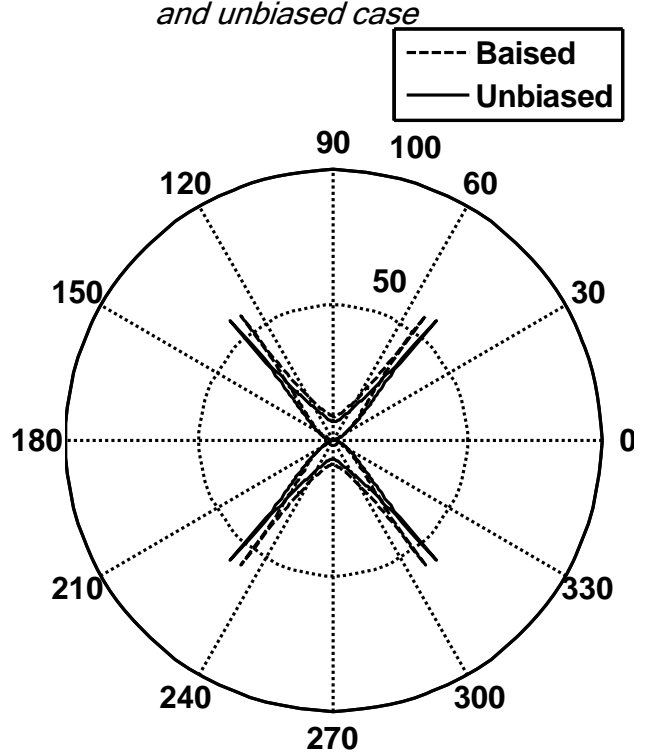

Fig. 5. Comparison of radiation pattern of 8 elements circular array of circular patches microstrip antenna with RHCP for biased and unbiased case

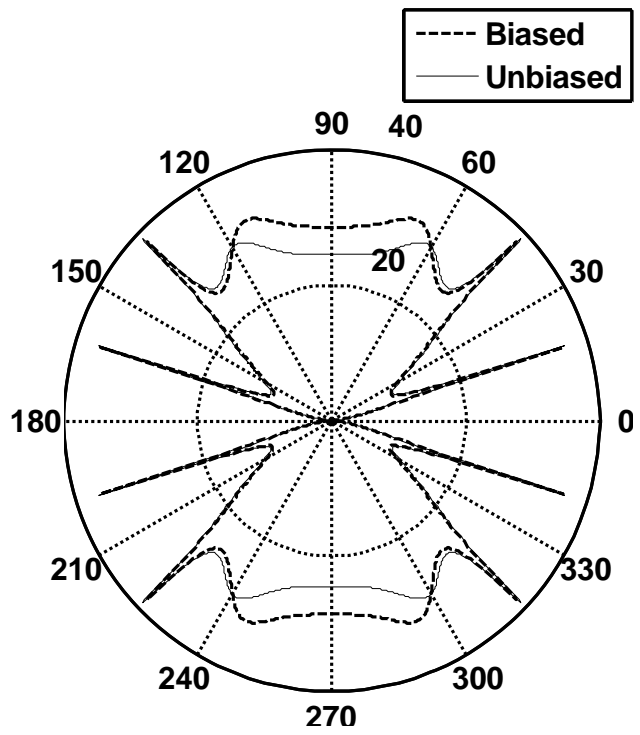

Research article

(C) Indian Society for Education and Environment (iSee)
"LiTiMg ferrite substrate" http://www.indjst.org
Naveen et al. Indian J.Sci.Technol. 
Table 1 \& 2 respectively. Using SSRT we have synthesized LiTiMg polycrystalline ferrite substrate for 8 elements circular array antenna at $10 \mathrm{GHz}$. of microwave frequency range. Some salient features of this array geometry are summarized as follow:

-E-plane comparison shows that on biasing, the radiation patterns becomes directive in nature and direction of lobes vary with changing biasing field.

- Array pattern comparison shows that on biasing, the radiation power is slightly increase on applying external biasing field.

- It is evident from the dispersion curve that, for the given parameters, the cut-off limit is between $1 \mathrm{GHz}$. to $2 \mathrm{GHz}$. and tunable resonant limit is about $2 \mathrm{GHz}$. to $10 \mathrm{GHz}$. This property of antenna shows its switchable and tunable capability which can be varied as per requirement.

-When the antenna is biased with DC magnetic field the parameters show that the directivity gain and radiation power are appreciably increase which enhances the scanning power as well as radiation power of array antenna.

- The size of patch is reduced considerable $35 \%$ comparable when designed on Quartz substrate. This reduction would certainly have a wide use in creating a miniaturization of an antenna system which has a potential application in space and cellular communication.

\section{References}

1. Batchelor JC and Langley RJ (1997) Beam scanning using microstrip line on biased ferrite. Elec. Lett. 33, 8.

2. Bharadwaj V, Tiwari V, Sharma KB, Saxena VK, Saini JS and Bhatnagar D (2001) Radiation from switchable ferrite based equilateral triangular microstrip antenna. Proc. Nat. Conf. on Microwaves. A\&P (Jaipur).

3. Balh IJ and Bhartia P (1980) Microstrip antennas. Artech house, Norwood, MA.

4. Balanis CA (1997) Antenna theory, John Wiley \& Sons, Inc.

5. Jain MK, lyengar SRK and Jain RK (1993) Numerical method for scientific and engineering computation, Wiley eastern Ltd., New Delhi.

6. Pozar DM (1992) Radiation and scattering characteristic of microstrip antenna on normally biased ferrite substrate. IEEE Trans. AP-40. pp:1084-1092.

7. Pourush PKS and Dixit L (1998) A $2 \times 2$ Element planar phased array of circular microstrip antenna on Ni-Co ferrite substrate at $10 \mathrm{GHz}$. I. J. Ratio \& Space Phy. 27, 289-226.

8. Pourush PKS et al. (2000) Microstrip scanned array antenna on YIG ferrite substrate. Proc. Int. Symp. on Antennas \& Propagation. Japan.
9. Pourush PKS and Dixit L (1998) Wide-Band scanned array of microstrip antenna on ferrite substrate. IJP.

10. Pran Kishan D, Sagar R, Chatterjee SN, Nagpaul LK, Kumar N and Laroia KK (1985). Optimization of $\mathrm{Bi}_{2} \mathrm{O}_{3}$ Contents and its role in Sintering of Lithium Ferrite. Adv in Ceramics. 16, 207.

11. Randhawa BS, Dosanjh HS and Nitendar Kumar (2007) Synthesis of lithium ferrite by precursor and combustion methods: a comparative study. J. Radio Anal. Nuclear Chemistry. 274(3), 581-591.

12. Sodha MS and Srivastav NC (1981) Microwave propagation in ferrimagnetics, Plenum press, NY.

13. Van Uitert LG (1956) Dielectric Properties and Conductivity in Ferrites. Proc. IRE, 44(10), 12941303. 